\title{
AC 2012-4564: LEARNING TO LEAD IN A GLOBAL COMMUNITY
}

\section{Mr. Joseph East, Michigan Technological University}

Joseph East is a fourth-year undergraduate student at Michigan Technological University graduating in April 2012. During his time at Michigan Tech, in addition to his primary studies in biology and mathematics, he has progressed through the Pavlis Leadership program and spent several years in the Nanotechnology Enterprise, holding several leadership roles including president of the enterprise. He will be attending the University of Michigan in Fall 2012, pursuing master's degrees in Industrial and operations engineering and health systems administration.

\section{Ms. Genevieve Gierke, Michigan Technological University}

Genevieve Gierke is graduating from Michigan Technological University in April 2012 with a bachelor's degree in biomedical engineering and a certificate in Global Technological Leadership from the Pavlis Institute for Global Technological Leadership. She is currently researching polymeric coatings for implantable devices through controlled release of nitric oxide at Michigan Tech.

\section{Ms. Mary Raber, Michigan Technological University}

Mary Raber currently serves as Associate Director for the Institute for Leadership and Innovation and Director of the Enterprise Program at Michigan Technological University. She has overseen the implementation and growth of the Enterprise Program at Michigan Tech since its inception in 2000, and is responsible for its overall coordination and development. Her responsibilities include corporate sponsorship development, interdisciplinary program evaluation and assessment, and workshop/course instruction in the areas of teaming and leadership. She is also actively involved in coordination, curriculum development, assessment, and instruction in the Pavlis Global Leadership program. She received her B.S. in mechanical engineering from the University of Michigan and an M.B.A. from Wayne State University and is currently working on her Ph.D. at Michigan Technological University. Before joining MTU, she held various engineering and management positions during a 15 year career in the automotive industry. 


\title{
Learning to Lead in a Global Community
}

\begin{abstract}
In response to a growing desire for students to possess leadership skills upon entering the workforce, an undergraduate cross-cultural, technological leadership institute was formed in 2005. Students in the Institute, many of whom are engineering majors, learn and develop their leadership abilities through a 25 -credit certificate program.

The curriculum allows students to explore leadership through coursework, interaction with industry leaders, development and implementation of projects, completion of a five-week international experience, and mentoring other students in the institute. Through coursework that explores topics such as global, ethical and technological leadership, teaming, cultural awareness and scientific communication, each student refines his/her personal leadership philosophy and gains the confidence and ability to lead in their professional careers.

By exploring the many facets of leadership through classroom study, practical application in real world humanitarian projects, and teaching others, it is believed that students will be better prepared to lead in post-graduate endeavors. This paper, written and presented by students of the program, presents the course curricula, activities, and international experience that are used in this program to develop leadership. Students will share their experiences and perspectives on the program, and successes and challenges associated with the program will also be reviewed with a goal of sharing beneficial lessons learned.
\end{abstract}

\section{Program Overview}

In 2005, Michigan Technological University formed a leadership institute with the mission of developing globally aware and technologically minded students with the drive to improve their environment during undergraduate studies and beyond. Providing an endowment for the program, Mr. Pavlis, a Michigan Tech alumnus, saw the need for undergraduate education to train proficient leaders in technological fields. Mr. Pavlis believes that higher education needs to prepare students to be successful in the global society through programs that develop "soft skills" as well as technical proficiencies. His views are shared by others who believe that beyond technical knowledge, leadership is the most necessary ability for engineers to be successful in professional life ${ }^{1}$. Indeed the NAE also advocated for leadership education among young engineers in its report on The Engineer of $2020^{2}$.

Students are admitted to the program by a selection committee which reviews the applicants' résumés, letters of recommendation, and responses to essay questions pertaining to their views on travel and global problems and solutions. Approximately 20-25 students are admitted from a 
diverse set of primary studies, and are maintained as one cohort unit throughout all four years. The four-year program focuses its' first three years on teaching leadership fundamentals and working on local projects culminating in a five week international immersion in the summer between students third and fourth year. Upon return students spend their final year mentoring younger cohorts and leading projects to provide continual improvement and assessment of the program.

As students progress through the program they gain the confidence to initiate improvements in their environments and lead technical teams because of their experiences with the international projects and the encouraging learning environment created by their faculty and peers. The ability to work independently of faculty supervision, particularly in the international immersion, gives hands-on experience and the challenge of completing projects and working with contacts to create projects for the upcoming years. This allows students to develop the confidence needed in their professional careers by their ability to be more aware of all stakeholders affected by a project, networking to provide solutions that are sustainable, and understanding that the community is held accountable for the success of the project. Through the encouragement of the faculty to take ownership over the program itself and develop ways to increase its effectiveness, students learn to take initiative and bring changes that will provide lasting benefit.

\section{Curriculum}

The classroom curriculum forms the base upon which the program is built. These courses are designed to educate students in areas not covered in their primary studies, encouraging them to understand their personal leadership philosophy and how to lead and work effectively in teams. In the first two years, students learn principles of effective leadership, through theory and examples, as well as develop teaming and scientific communication skills. In the third year, topics on ethical leadership and various leadership philosophies are explored. Students take courses in cultural awareness, foreign language fundamentals, and conducting research in another culture during the summer of their third year in preparation to live and work abroad during their international immersion. They also lead a week long high school leadership workshop during this summer, teaching the skills they have learned to others. The final year is spent working on capstone projects reflecting on the coursework and international experience and continuing the advancement of the program.

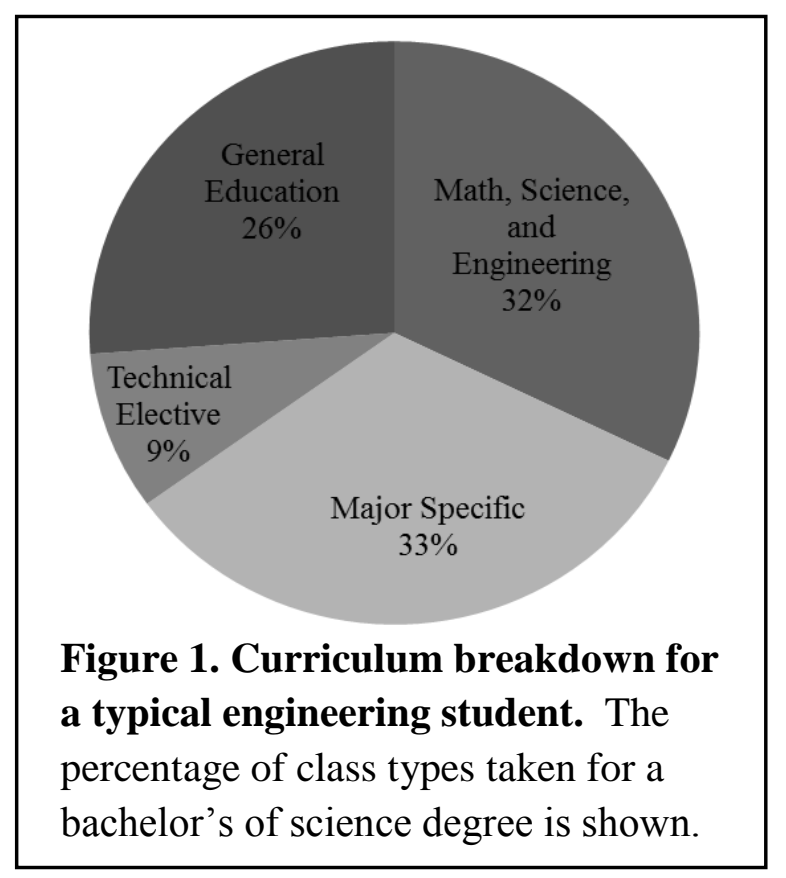




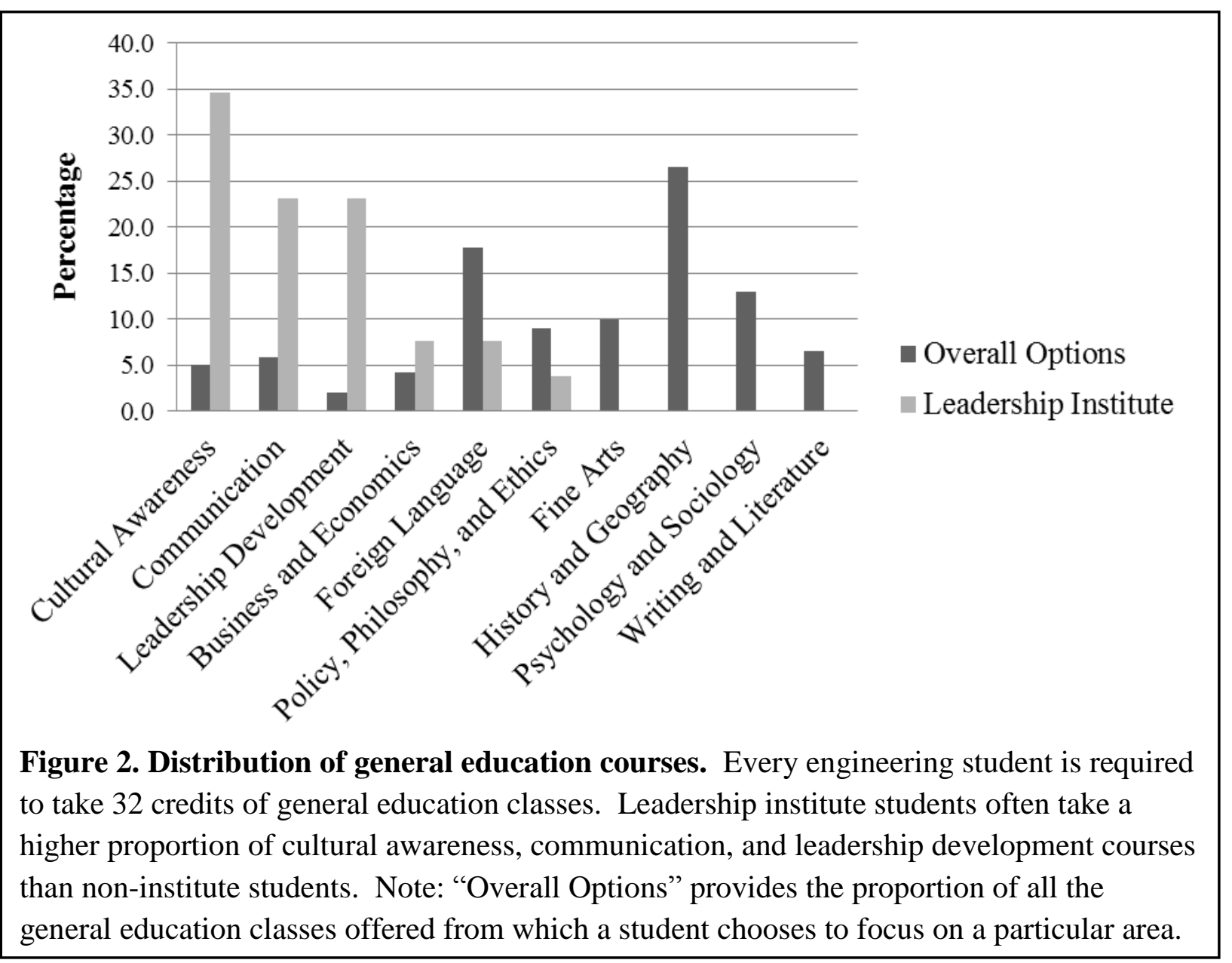

A typical engineering student's courses are composed of general math, science, and engineering $(32 \%)$, major specific courses (33\%), technical electives $(9 \%)$, and general education classes (26\%) (Figure 1). General education classes range from business to history to psychology. Many of the courses students take in the leadership program count for these general education classes and as such, tend to give students a higher proportion of leadership development, cultural awareness, and communication studies then their non-institute peers (Figure 2). In taking these classes the students spend time developing their own leadership philosophies and understanding how to work in teams before entering the workforce. Through proposing, developing and implementing projects on campus, students are encouraged to gain confidence in creating change within their communities and to grow in their ability to do so. For example, the Green Campus Enterprise was created and developed by students in the program and is now a part of a university-wide program that serves as an alternative to senior design projects for some engineering students. This organization researches ways to develop green technology on campus and works with the university to implement solutions to current sustainability problems. The enterprise is now run by non-institute students, showing that a sustainable program was created and was able to continue without the direct involvement of leadership students. 
Other examples of campus organizations started by institute students are Art Revolutionizing Tech (ART) and Tech Taking Education Abroad (TEA). ART focuses on making campus more aesthetically pleasing by addressing a sparse presence of visual arts. Tech TEA is an organization which brings in speakers to raise awareness and money for global education, especially for women in the Middle East.

The Institute feels that one of the necessary areas to learning leadership is through observation of, and interaction with other leaders. Current industry leaders and other inspirational speakers are invited to campus several times a semester to talk with the leadership program students and provide insight to their experiences and an environment of open discussion and debate about leadership skills. This also provides opportunities for networking by the students for projects within the institute or for their future career. Another form of networking is within the Institute itself. Senior students of the program help teach and mentor students in the younger cohorts and work closely with the third year students as they prepare to go on their international immersion experience. Through teaching, students are able to share their perspective on leadership and guide others in project ideas.

\section{International Immersion}

In the summer after their third year, students travel to a developing country to conduct humanitarian projects identified by the previous cohort and developed throughout their third year. Students work with local contacts and beneficiaries to develop projects brought forward by the community. They focus on making the projects beneficial and sustainable and often involve implementing an existing technology in one form or another. Ghana was chosen as the first international location because of university contacts and has continued for the past four years (2008-2011). Argentina was also chosen because of university contacts and has been a site for the last two years (2010-2011). These sites have provided the Institute with valuable lessons on how to conduct this portion of the program. Chennai, India is being added as a third project site in 2012, and is again chosen as a site because of university contacts. This will allow for a new cultural perspective to be given to the students.

A principle feature of the international experience is to have the students live in the communities in which they work without the guidance of a faculty member. In addition to conducting project work they also live, travel, and communicate for a majority of the time on their own, a unique feature of the program. This allows for a greater understanding of the day to day life in a foreign culture and how to work as team. The ability to live independently for five weeks is made possible by an in-country contact that is employed by the Institute and is always available for guidance and support. These contacts have also been great sources of project ideas and connections to communities and organizations within the country. 
The projects conducted are developed with the receiving communities to address an area of need. To date these projects have largely focused on basic humanitarian needs such as education, water purification, electricity supply, and agricultural improvements. The biggest challenge in these projects has been to understand how to design and incorporate them into the communities in a way that will be beneficial for the community, and thus have a lasting impact. Thinking about how to implement projects in a sustainable way in which the community takes ownership over the projects encourages the students to spend time developing not only the technical solution to the problem, as is often the case in traditional engineering projects, but also to consider all the stakeholders in the project and how it will impact the recipients.

\section{Effect of the Pavlis Leadership Program on Student Growth and Development}

Many programs and universities offer international experiences. What sets the Pavlis Institute apart is that students live and conduct projects abroad over five weeks, four of which are without a faculty advisor present, which is more independent than the more traditional study abroad experience. Students have to become proficient in their project field, which is often not directly in their primary field of study, in order to lead a team and effectively communicate with many stakeholders. This allows for the growth of the students professionally, culturally, and crossdisciplinary. A study of 20 graduated members of the institute showed that combined with the communication skills built in the first three years of coursework, this model has shown to be very effective in the personal growth and development of the students in the fields of communication and leadership. Students graduate from the program believing they have learned many of the skills needed in leading teams in their professional careers during their time in the leadership program (Figure 3).

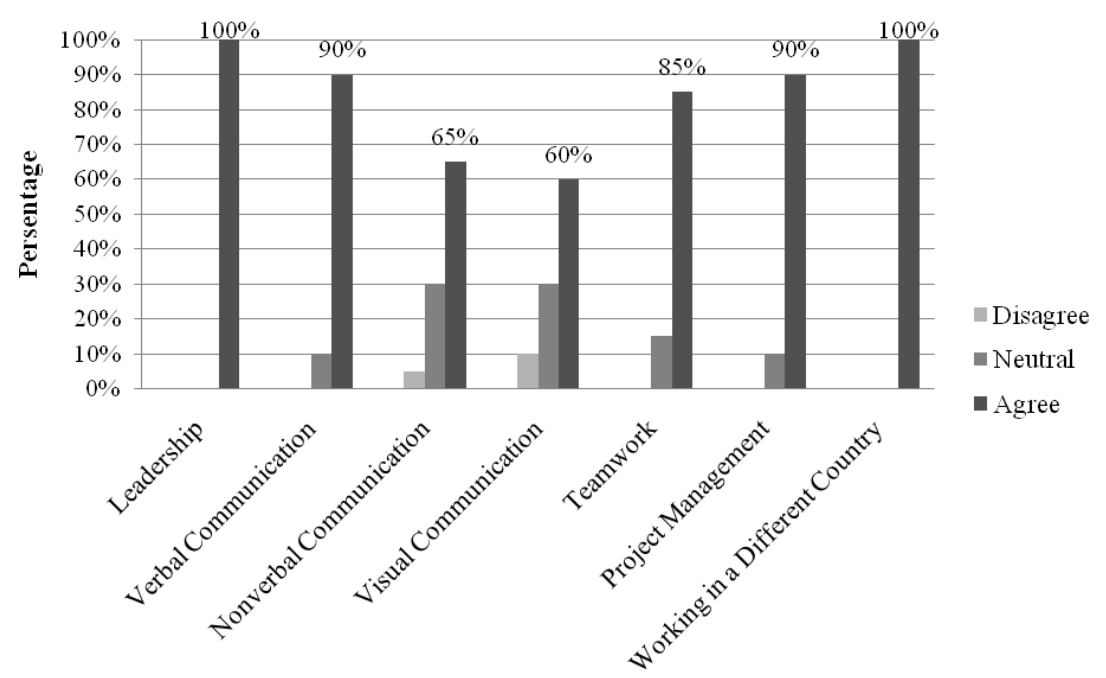

Figure 3: Leadership institute skill development. Graduates of the program indicated the effectiveness of the institute in promoting the development of several leadership, teaming and communication skills $(n=20)$. 
Each member of the institute brings different backgrounds, knowledge, and goals to the program providing for great collaboration among all students. This also leads to different experiences with the program, each gaining skills needed to help them in their professional lives. Below is one authors experience entering the program, how it impacted her undergraduate education and the benefits it will serve in her future career.

"Entering into this program, I had already travelled to Japan for a one month homestay at the age of 14, did a water survey in Nicaragua, and travelled to the Czech Republic. I considered myself involved in my community as a participant in 4-H and Little Brothers Friends of the Elderly. I was president of the National Honor Society at my high school and an instigator of change in policies in my high school as well as an inspiration for high achievement for my fellow classmates. To me, joining a leadership program seemed like the next logical step, but I had no idea how much of an impact it would make on my communication skills, leadership abilities, and general outlook on life.

Throughout the first three years of coursework in the program, I was continually challenged to reflect on my own personal growth and development. Without the program I know that I would have thought I was 'good enough' at all of the skills previously mentioned. As soon as this thought pops into ones head, that is the end of any hope that one can make a difference. I think that is one of the biggest lessons learned through the program's coursework. I feel that having a group of people who know me and can give feedback so I can grow is the only way to do this. I cannot think of a better way to foster this mentality than having a cohort of 20 people that are always there for me and growing with me.

We were also challenged to make change. Several times students would have strong opinions about how the program should be run. This was accepted and encouraged, which is a very different mentality than any other class I have been in. This was intimidating at first, but once we saw that our thoughts and opinions were taken seriously it became evident that this program could only be what we made it to be.

Last summer I travelled with nine other classmates to Ghana. Here we implemented a variety of projects. The project that myself and another student were in charge of dealt with agriculture. This was a big leap for me because I am currently studying biomedical engineering. What I learned is that I am able to lead a project that I have little to no expertise in and work with a foreign government, research university, and farmers to coordinate their common interests and help interpret to each stakeholder how this agricultural project could affect them. What this means is that I could serve as a liaison between all of these separate groups to help grow interest in this agricultural project to help ensure its success. Although I didn't have an opportunity to 'get my hands dirty' that often while working on the project, it showed me that leadership is 
more about making the connections and explaining to each participant why something is important to the other, rather than just doing physical labor. This really shifted my view of leadership. It makes more sense, now that I have seen and practiced this, but it was not an apparent thought to me prior to this experience.

Now that I have had this opportunity, I feel that I am much more comfortable and confident in my leadership abilities. Prior to this, I felt that I always had to do everything myself, which is not effective leading. I am now able to take a group of people and connect their common interests to inspire them so the work gets completed. This is easy to see in my experience in my engineering senior design project this year. I became the leader for the group and have been able to motivate others to do their best work and to create a product that not one of us could have created alone.

What I have gained from this experience is the ability and confidence to work with a group of individuals to reach a common goal and inspire them to do so. I also feel that I am able to work on any technical project because I have been taught to learn quickly and look at the big picture to accomplish goals. I feel that this has made me a better engineering student (and soon to be engineer) because I am given the technical knowledge in my required coursework and leadership skills through the Pavlis Institute. By participation in the program I have gained the skills necessary to implement engineering solutions by working with a diverse group of people building on the views, cultural diversity, and areas of expertise of all involved. This has been an invaluable experience and is sure to make an impact in my future career."

Below is another authors experience regarding his time in the leadership program, how he has grown as a leader due to the program, and how the benefit brought not only his future career, but his leadership roles while in undergraduate education.

"Upon entering the program I was excited to be in a class with so many other students who were eager to learn about leadership and gain the ability to positively impact the community they were in. Spending time both in and out of the classroom with peers (and soon friends) that shared my ambition to make a difference quickly created a culture that I was glad to be a part of. Being in class through all four years with the same group of students has been a major catalyst for my personal leadership development. By knowing everyone in my cohort, I am comfortable giving them advice on how to be leaders and accepting advice from them. We also have learned how to effectively work with different personalities and have the confidence to address areas of conflict which will prove invaluable in our future careers.

During the first few years I did not take much initiative to be a part of shaping the institute and it was only when I realized that we were not only supposed gain leadership ability through the program but we were supposed to be leaders of the program that I began to actively help build the program itself up and work to make the courses, fundraising activities, and involvement with 
younger cohorts a high priority. Doing so has led me to realize the importance of practicing real leadership now, and not just in my future career. Being purposeful in caring about and working towards the success of the people and organizations I am a part of has been one of the main lessons I have learned during my time in the program and I believe this is a key aspect of the success of this program.

I brought this eagerness to work with others to achieve our goals and the teaming and communication knowledge I gained through my classes to my experience in the Nanotechnology Enterprise. Enterprises function as student run, 'real world' companies on campus and provide both hands on technical experience and skills in managing projects with budgets, timelines, and external stakeholders. As a biological science major, being a non-engineer in the enterprise was a challenging and rewarding experience. Through my time in the enterprise I participated and lead several project teams and was the president of the enterprise during my third year. By participating in the leadership program I gained confidence to learn about and participate in projects outside my field of study and lead others to achieve tangible results for external stakeholders.

Last summer I traveled to Ghana and worked primarily on implementing education projects at several sites and researching health projects for future groups. Seeing disparities in access to both education and healthcare in different areas in Ghana helped me see that no problem has one simple solution. It is necessary to engage with those who are requesting the project, those who are impacted, and other stakeholders to achieve a real solution that will have a lasting impact. Living in Ghana largely on our own, and having to barter for food, cook, use public transportation to travel, and communicate with the Ghanaians provided a much more enriching experience than the projects alone would have. A primary lesson I gained from my international experience is to be aware of other cultures and ways of thinking. Another lesson was the experience that came with living and working with nine other people for five weeks. Both of these have expanded my ability to relate to others and be successful in project teams.

Throughout my time in the leadership program I gained confidence and understanding in undertaking projects and working and leading teams. My experience has provided me with countless insights on how I lead others and work effectively on setting and achieving goals. I feel better prepared to listen and understand others and know how to encourage them to seek their best as well. By learning from students, faculty, and other supporters of the program I am able to bring my experiences to my future studies and career and help others to be leaders as well.

These reflections exemplify the necessity for independence while completing projects and the benefits of this experience for the personal and professional skills of the students which complete the program. This is what we feel makes this program unique and a model for others. The 
program is neither complete, nor is it perfect, but its' malleable nature helps make it successful. This allows adaptation as students and faculty change, sustaining it as a valuable institutional program.

\section{Future Direction of the Program}

Due to the continual transformation of the program in accordance with student feedback, curriculum changes are being made in the upcoming year. Courses are currently separated among cohorts, with limited in-class interaction between different cohorts. Student desire for greater collaboration has led to the development of an all-cohort course each year allowing for more collaborative learning and continuity of the project efforts. This will engage more students in mentor/mentee relationships, and also create a diverse environment of students in many disciplines and ages, a quality not found in many other courses. Another change is moving the core theoretical leadership class to the first semester, instead of having it during the third year. It was placed in the third year to allow students to develop their own leadership philosophies, teaming abilities, and project development before an in-depth study of leadership theory, however through student feedback it is believed that these goals will be more encouraged by moving the course to the first semester. Doing so will result in educating students about leadership philosophy earlier and allow for more effective reflection and development of personal leadership philosophies throughout the program, and helping other members of the cohort to do so as well.

Each level of progression in school and careers allows for a new perspective on the courses that should be offered and what direction they should take. All courses are approved by the university and fulfill several areas of students required credits, but the flexibility of the design of the program is a positive feature of the program.

\section{Building a Leadership Program}

Participating in a developing program has provided us with a unique opportunity to be at the center of its formation and improvement, which has shown us what makes an effective program and how to continually strive to improve the organizations in which we are involved. Students have advised on the curriculum, designed improvements to the program website, formed a leadership book club to increase cross-cohort communication, and established connections with alumni to begin program assessment. By taking ownership over their time in the leadership institute, students develop themselves further to be proactive in their future professional careers.

We, along with the program faculty, believe that developing an involved leadership program at other academic institutions would be highly beneficial and also very feasible. While the program was started by an endowment from Mr. Pavlis, it has additional sources of funding to sustain the 
program. For example, much of the summer tuition costs for courses during the summer of students third year (13 credits) goes back to the program per university policies. While this may not be the case at all academic institutions it is one way for the leadership institute to maximize the resources it has. The institute often partners with other departments and organizations on campus when inviting guest speakers to spread the financial costs. Students raise all the necessary money to cover their project initiatives and seek collaboration with outside organizations and individuals to support their projects abroad. Financial constraints in initiating and sustaining a four year program such as this are by no means negligible; however we believe the benefits acquired by the students and the university alike merits such efforts.

\section{Conclusion}

Those who have completed this program, state unequivocally, that they feel more well-rounded than peers in their same field of study. They have been given more opportunities to develop as leaders and feel better prepared for their future endeavors. By participation in this program students are also more open to communication with those in other cultures and many institute students are involved in multicultural activities within the university and outside of the institute. Commenting on how the program affected their career path one student said,

"[My career] goal has been inspired by two of my defining undergraduate accomplishments, founding an educational community center in Ghana, Africa and launching a non-profit to support education for young women in the Middle East. These accomplishments that have infused my education with enriching, engaging, and lifealtering experiences... In the midst of cultural immersion course work, I realized that I had been living my entire life on the ground floor of a library that contained an upstairs filled with: unique cultures, diverse languages, and alternative ways-of-being."

With a strong desire to change their environment for the betterment of those around them, many institute students are involved and influential in other organizations and departments on campus. Although the program is young, students feel that the preparation received will benefit their future life and careers, and with each passing year, the program will develop into something unique to those students continuing to improve greatly with time. Our hope is that other academic institutions may use these experiences as a model for their respective programs. In particular we hope other these programs seek to continually value the voice of the students and express a willingness to encourage change and improvement. 
(1) Bowman, B.A., and J.V. Farr, "Learning to Lead: A Lifelong Pursuit," Proceedings from the 1998 Annual American Society of Engineering Management Conference, (1998), pp.158-163.

(2) National Academy of Engineering. The Engineer of 2020: Visions of Engineering in the New Century. National Academies Press. 2004. 